\title{
Mobility care in nursing homes: development and psychometric evaluation of the kinaesthetics competence self- evaluation (KCSE) scale
}

\author{
Heidrun Gattinger ${ }^{1,2^{*}}$, Beate Senn ${ }^{3,4}$, Virpi Hantikainen ${ }^{5,6}$, Sascha Köpke', Stefan Ott ${ }^{8}$ and Helena Leino-Kilpi ${ }^{9,10}$
}

\begin{abstract}
Background: Impaired mobility is a prevalent condition among care-dependent persons living in nursing homes. Therefore, competence development of nursing staff in mobility care is important. This study aimed to develop and initially test the Kinaesthetics Competence Self-Evaluation (KCSE) scale for assessing nursing staff's competence in mobility care.

Methods: The KCSE scale was developed based on an analysis of the concept of nurses' competence in kinaesthetics. Kinaesthetics is a training concept that provides theory and practice about movement foundations that comprise activities of daily living. The scale contains 28 items and four subscales (attitude, dynamic state, knowledge and skills). Content validity was assessed by determining the content validity index within two expert panels. Internal consistency and construct validity were tested within a cross-sectional study in three nursing homes in the German-speaking region of Switzerland between September and November 2015.

Results: The content validity index for the entire scale was good (0.93). Based on a sample of nursing staff $(n=180)$ the internal consistency results were good for the whole scale (Cronbach's alpha $=0.91)$ and for the subscales knowledge and skills $(a=0.91,0.86)$, acceptable for the subscale attitude $(a=0.63)$ and weak for the subscale dynamic state $(a=0.54)$. Most items showed acceptable inter-item and item-total correlations. Based on the exploratory factor analysis, four factors explaining 52\% of the variance were extracted.

Conclusion: The newly developed KCSE scale is a promising instrument for measuring nursing staff's attitude, dynamic state, knowledge, and skills in mobility care based on kinaesthetics. Despite the need for further psychometric evaluation, the KCSE scale can be used in clinical practice to evaluate competence in mobility care based on kinaesthetics and to identify educational needs for nursing staff.
\end{abstract}

Keywords: Kinaesthetics, Mobility limitations, Clinical competence, Educational measurement, Nursing

\section{Background}

People living in nursing homes and residential facilities often require assistance with mobility including walking, transferring, and bed mobility, as well as with movements needed to accomplish activities of daily living (such as dressing, personal hygiene, or toileting) [1]. In this article, we will refer to this kind of assistance as

\footnotetext{
* Correspondence: heidrun.gattinger@fhsg.ch

${ }^{1}$ Finnish Doctoral Programme in Nursing Science, Department of Nursing Science, University of Turku, Turku, Finland

${ }^{2}$ Institute of Applied Nursing Sciences, University of Applied Sciences FHS St. Gallen, Rosenbergstrasse 59, Postfach, 9001 St. Gallen, Switzerland

Full list of author information is available at the end of the article
}

mobility care [2]. Mobility impairment can result from age-related slowly progressive functional loss due to neuromuscular, cognitive or sensory decline [3] or can occur suddenly after an acute event such as a stroke [4].

Mobility is necessary for participation in meaningful social, cultural, and physical activities. Impaired mobility restrict participation in social activity leading to isolation and loneliness [5]. Furthermore, loss of mobility is associated with a persistent decline in function and physical activity and is a risk factor for pressure ulcers, falls, urinary incontinence, and malnutrition [6]. Because mobility contributes to the residents' health and quality of life, it 
is important to maintain and enhance this mobility [7]. Therefore, nurses (registered and licensed practical nurses) and other care team members who work in direct care (nurse assistants and nursing aides) - hereinafter referred to as nursing staff - should have the knowledge and skills that allow them to provide high quality mobility care [8]. Nursing staff is required to understand the residents' mobility capacities and to use mobility enhancing strategies and methods encouraging residents, where possible, to move to their highest level of independence [9]. Different nursing staff training programs have been tested in order to reach these goals; for example, an educational intervention in natural mobility [10] and a person-centered approach with mobility enhancing strategies, which include how to interact and communicate with residents and how to promote the correct biomechanics [11].

Another comprehensive training concept is kinaesthetics, it provides theory and practice about movement foundations that comprise activities of daily living. The kinaesthetics approach includes person-centeredness, personalized interaction and communication as well as appropriate support of functional mobility [12, 13]. In kinaesthetics training, participants learn to understand human movement and a mobility impaired persons' possibilities to participate in activity of daily living based on the six concepts interaction, functional anatomy, human movement, human functions, effort, and environment $[12,13]$.

Competence criteria relevant to provide high quality mobility care are represented in knowledge, skills, attitude and a dynamic state. Knowledge comprises theoretical understanding of safe and optimal handling during movement support of a mobility impaired person [11, $14,15]$. Skills include effective communication, attentive interaction, ability to support a care-dependent person's movement in an optimal way, nursing staff member's ability to adapt their own movement, and adaptation of the environment in order to enhance the mobility impaired person's individual way of moving [15-19]. Attitude includes interest and openness toward the caredependent person and a commitment to personal development $[10,15,17,18]$. Dynamic state includes analysis and reflection of mobility support situations as well as provision of learning situations $[15,17,18,20]$.

However, high quality mobility care is not necessarily a clearly recognized nursing remit [21] and the training and support that nursing staff need regarding mobility care to adequately fulfil their role are lacking $[8,22]$. In order to identify the educational needs regarding nursing staff's knowledge, skills, attitude, and dynamic state in mobility care and to guide further practical and theoretical training, an assessment of nursing staff competence in mobility care is essential.
Former self-evaluation instruments were developed in order to evaluate specific training concepts, e.g. natural mobility [10]. Five instruments were identified that assess nursing staff's knowledge and skills regarding learned principles [11, 23-26]. Instruments developed by Betschon et al. (2011), Kindblom-Rising et al. (2011) and Kneafsey and Haigh (2009) include questions for assessing participants' attitude and motivation and perception of their role in mobility rehabilitation. Although, most of these instruments underwent preliminary testing regarding face and/or content validity with experts and/ or nursing staff $[11,24-26]$, only few have reported additional psychometric testing $[10,26]$. No selfevaluation instrument was identified that includes all areas of nursing staff's competence in mobility care based on kinaesthetics.

Therefore, the goal of the current study was to develop a valid and reliable self-evaluation instrument in order to determine nursing staff competence in mobility based on kinaesthetics [15]. The present article summarizes the development of the Kinaesthetics Competence SelfEvaluation (KCSE) scale, the testing of content validity and the analysis of internal consistency and construct validity of the scale.

\section{Methods \\ Construction of the KCSE scale}

First, a blueprint with item pool and response scale was established based on a concept development study [15]. In an iterative process, the items and response scale were refined between January and June 2015. Subsequently, a scale with four categories (knowledge, skills, attitude, and dynamic state) and 28 items was assessed for content validity. Content validity was evaluated first with a panel of nine experts with kinaesthetics trainer certificates and varied experience in health care (Table 1). First, the expert panel rated each item on a 4-point Likert scale $(1=$ not relevant, $2=$ somewhat relevant, $3=$ quite relevant, $4=$ highly relevant). Second, the experts evaluated the clarity of items. Finally, the experts were asked for further comments / suggestions to improve the scale. Items with inter-rater agreement for relevant and somewhat relevant items of $\geq 0.78$ were accepted for inclusion in the scale [27]. Based on these results, two items were deleted, 20 items reworded, and two new items added. The revised scale was re-evaluated with a second panel of five experts (Table 1) using the same procedure.

In the revised scale, the item content validity index (ICVI) [27] was 1.0 for 18 items and 0.8 for 10 items, and the content validity index for the entire scale (S-CVI) [27] with 28 items was 0.93 .

In order to assess comprehensibility and usability, the questionnaire was pilot tested with a group of nursing staff ( $n=6$; two registered nurses, two licensed practical 
Table 1 Sociodemographic characteristics of experts in both panels

\begin{tabular}{|c|c|c|}
\hline \multirow[t]{2}{*}{ Characteristics } & \multicolumn{2}{|c|}{ Content validity testing } \\
\hline & $\begin{array}{l}\text { 1. Expert panel } \\
(n=9)\end{array}$ & $\begin{array}{l}\text { 2. Expert panel } \\
(n=5)\end{array}$ \\
\hline
\end{tabular}

Age: mean (SD)

\begin{tabular}{|c|c|c|}
\hline In years & $51.4(4.25)$ & $51.4(2.51)$ \\
\hline \multicolumn{3}{|c|}{ Working experience with kinaesthetics: mean (SD) } \\
\hline In years & $19.9(6.74)$ & $19.6(2.97)$ \\
\hline \multicolumn{3}{|l|}{ Gender (n, \%) } \\
\hline Female & $7(78 \%)$ & $3(60 \%)$ \\
\hline Male & $2(22 \%)$ & $2(40 \%)$ \\
\hline \multicolumn{3}{|l|}{ Nationality (n, \%) } \\
\hline Swiss & $7(78 \%)$ & $4(80 \%)$ \\
\hline German & $2(22 \%)$ & $1(20 \%)$ \\
\hline \multicolumn{3}{|l|}{ Profession (n, \%) } \\
\hline Registered nurse & $5(56 \%)$ & $5(100 \%)$ \\
\hline Licensed practical nurse & $2(22 \%)$ & 0 \\
\hline Physiotherapist & $1(11 \%)$ & 0 \\
\hline Speech therapist & $1(11 \%)$ & 0 \\
\hline \multicolumn{3}{|l|}{ Kinaesthetics training ${ }^{\Delta}(\mathrm{n}, \%)$} \\
\hline Trainer level 1 & 0 & $1(20 \%)$ \\
\hline Trainer level 2 & 0 & 0 \\
\hline Trainer level 3 & $6(67 \%)$ & $3(60 \%)$ \\
\hline Train the trainer & $3(33 \%)$ & $1(20 \%)$ \\
\hline \multicolumn{3}{|l|}{ Main place of work* $(n, \%)$} \\
\hline Long-term care for elderly & $6(67 \%)$ & $5(100 \%)$ \\
\hline Home care & $3(33 \%)$ & 0 \\
\hline Hospital care & $2(22 \%)$ & $1(20 \%)$ \\
\hline $\begin{array}{l}\text { Long-term care for disabled } \\
\text { persons }\end{array}$ & $5(56 \%)$ & $1(20 \%)$ \\
\hline
\end{tabular}

$S D$ standard deviation; ${ }^{\boldsymbol{}}$ According to European Kinaesthetics Association, trainer levels are based upon each other and train the trainer level is the highest level [24]; ${ }^{*}$ includes double entries (added up to more than 100\%)

nurses, and two nursing aides with a mean work experience in long-term care of 8 years, SD 7.4), working in two medium-sized (around 80 beds) nursing homes. The participants evaluated the clarity of instruction, item wording, and the questions about sociodemographic characteristics and background variables and, if they had any concerns, their suggestion for revision. A specification in one sociodemographic question and a further explanation in the instruction (to not set the cross between boxes) were made based on the participants' responses.

\section{Description of the final KCSE scale}

The final KCSE scale comprises 28 items assessing nursing staff's attitude (9 items) and dynamic state (5 items) about mobility enhancing care in terms of kinaesthetics, their knowledge of the kinaesthetics concept (7 items), and their self-perceived use of the kinaesthetics principles (=skills) (7 items) (Fig. 1). Items have four response options in terms of agreement (disagree, somewhat agree, agree, strongly agree), frequency (never, sometimes, almost every time, every time), and level of quality (not at all, somewhat, good, very good). Single items score between 1 and 4, with higher scores indicating higher self-evaluated competence in mobility care based on kinaesthetics. The instrument has been developed in German [28].

\section{Psychometric evaluation of the KCSE scale}

Psychometric evaluation of the KCSE scale included testing of reliability (internal consistency) and construct validity [29] within a cross-sectional study.

\section{Settings, sample, and data collection}

The study was conducted in three nursing homes in the German-speaking part of Switzerland between September and November 2015. The nursing homes were purposefully selected based on the following criteria: medium-sized nursing home (between 50 and 100 beds), private or public, not exclusively providing care for demented persons and a minimum of half the nursing staff members passed a kinaesthetics training. These criteria are representative of nursing home facilities in the German-speaking region of Switzerland [30].The KCSE scale was handed out to all German-speaking nursing staff (i.e., registered nurses, licenced practical nurses, nursing aides and nursing students) working in direct care by the head nurse. Data was collected over a 4week period, and a reminder was sent to the nursing homes after another two weeks. The completed KCSE scale was returned in a sealed envelope to boxes that were placed in the participating wards.

\section{Data analysis}

The data was analyzed using SPSS 22 (IBM Corp, 2013). Item level, subscale level, and total-scale level analyses were conducted using descriptive statistics (frequencies, means, and standard deviation). For the KCSE subscales, mean scores were calculated (range 1-4). The total score was calculated by summing the mean scores of the subscales (range 4-16).

Internal consistency was calculated using Cronbach's alpha coefficients. Cronbach's alpha coefficients less than 0.60 are considered low, indicating limited instrument consistency [31]. Item analyses were performed by computing the corrected item-total correlation for the items in the subscales and an inter-item correlation. Item-total correlations of at least 0.20 were regarded as acceptable [32], as were inter-item correlations of $r>0.20$ and $<0.70[32,33]$. 


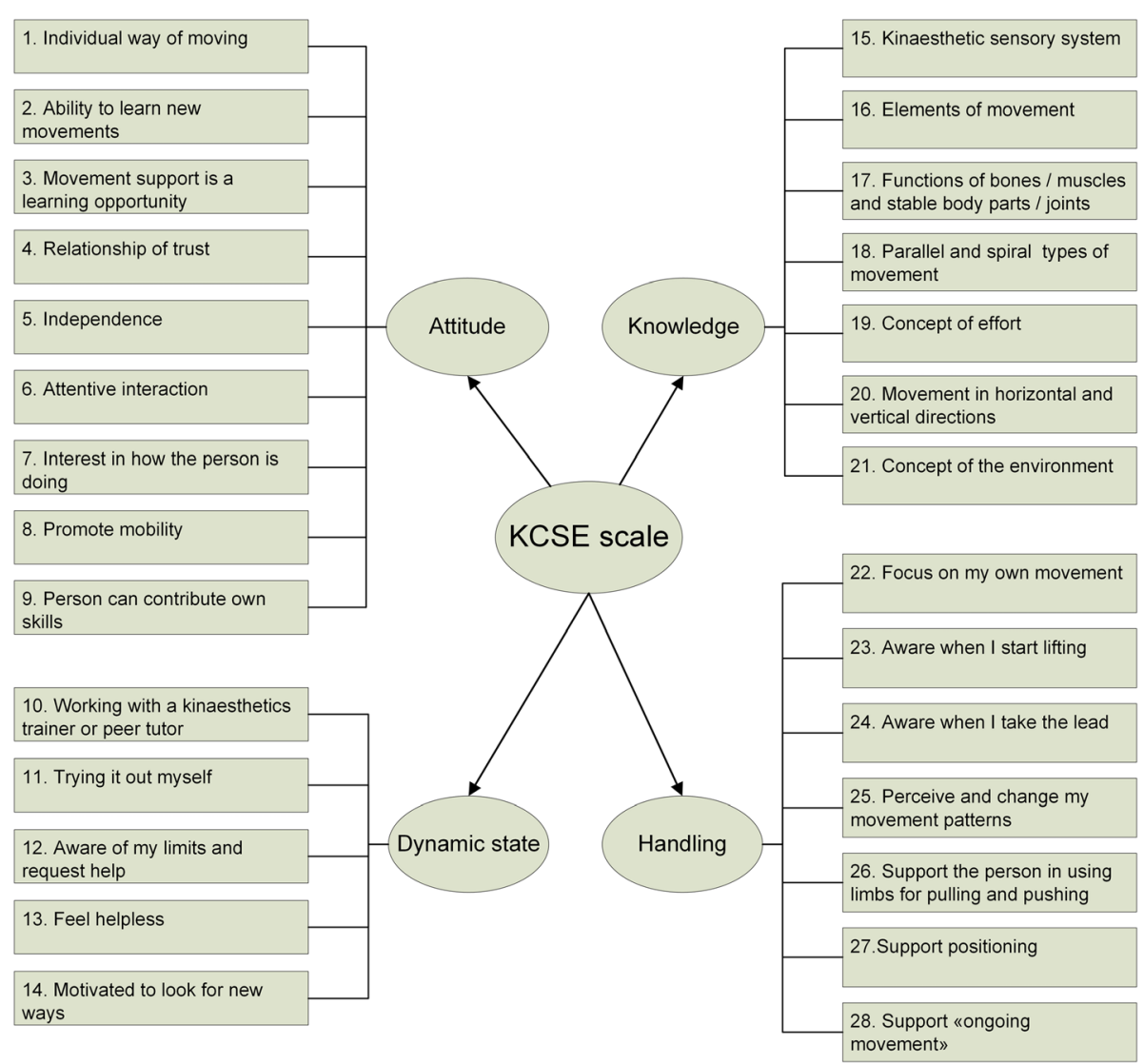

Fig. 1 Structure of the KCSE scale

The construct validity of the KCSE scale was investigated with exploratory factor analysis in order to explore the underlying structure of the 28-item KCSE scale. To confirm the adequacy of the sample size for factor analysis, the variable to subject ratio was calculated; 1:5 was considered the minimum and 1:10 sufficient [34]. Prior to performing factor analyses, the suitability of the data was assessed using the Kaiser-Meyer-Olkin (KMO) criterion with a recommended value of 0.5 or above and Bartlett's test of sphericity with a $p$-value below 0.05 [35]. Principal component analysis (extraction method) was conducted using direct oblimin rotation in order to account for correlations between factors. Eigenvalues greater than one (Kaiser criterion) and the scree plot were used to determine the number of factors [35].

\section{Results}

\section{Sample characteristics}

From the total sample of 214 nursing staff members, 180 $(=\mathrm{n})$ returned the questionnaire $(84 \%)$ (Table 2$)$.

\section{Scale descriptive and internal consistency results}

Nursing staff's mean sum score (range 4-16) on the KCSE scale was 13.0 (SD 1.437). Mean scores that participants attained in the subscales (range 1-4) ranged from 3.0 to 3.6 (Table 3).

The reliability of the scale was assessed by Cronbach's alpha and item analysis including item-total and interitem correlations. The entire KCSE scale shows high internal consistency with a Cronbach's alpha coefficient of 0.91 . For the subscale levels, the coefficients were 0.63 for attitude, 0.54 for dynamic state, 0.91 for knowledge, and 0.86 for skills (Table 3). Regarding the item analysis, $86 \%$ of all items showed higher item-total correlations than the criteria set $(r>0.20)$ (Table 3). The lowest correlations were obtained for item 1 (individual way of moving), item 4 (relationship of trust), item 12 (aware of my limits and seek help), and item 13 (feel helpless) (Table 4). The aimed inter-item correlations of $r>0.20$ and $<0.70$ was reached for $33-100 \%$ of the subscale items (Table 3).

\section{Structure of the instrument}

An exploratory factor analysis was used to explore the underlying factors of the newly developed KCSE scale. The Kaiser-Meyer-Olkin measure verified the sampling adequacy for the analysis $(\mathrm{KMO}=0.89)$. Bartlett's test was significant $(p<0.001)$ and indicated 
Table 2 Sociodemographic and professional characteristics of participating nursing staff $(n=180)$

\begin{tabular}{|c|c|c|c|c|}
\hline Characteristics & $\mathrm{n}$ & $\%$ & Mean (SD) & Range \\
\hline Age (years) & 175 & & $41.8(13.23)$ & $15-64$ \\
\hline Length of experience in nursing home care (years) & 175 & & $12.9(9.99)$ & $0-37$ \\
\hline Length of working in the current institution (years) & 176 & & $8.3(7.93)$ & $0-36$ \\
\hline \multicolumn{5}{|l|}{ Gender } \\
\hline Female & 159 & $88 \%$ & & \\
\hline Male & 21 & $12 \%$ & & \\
\hline \multicolumn{5}{|l|}{ Educational level } \\
\hline Registered nurse (BSN, Diploma) & 58 & $32 \%$ & & \\
\hline Licensed practical nurse & 30 & $17 \%$ & & \\
\hline Nurse assistant & 80 & $44 \%$ & & \\
\hline Nursing student & 7 & $4 \%$ & & \\
\hline Missing data & 5 & $3 \%$ & & \\
\hline \multicolumn{5}{|l|}{ Level of employment } \\
\hline $80-100 \%$ & 100 & $56 \%$ & & \\
\hline $50-70 \%$ & 49 & $27 \%$ & & \\
\hline $20-40 \%$ & 27 & $15 \%$ & & \\
\hline Missing data & 4 & $2 \%$ & & \\
\hline \multicolumn{5}{|l|}{ Kinaesthetics training [32] } \\
\hline No training & 16 & $9 \%$ & & \\
\hline Basic training course & 69 & $38 \%$ & & \\
\hline Advanced training course & 66 & $36 \%$ & & \\
\hline Peer tutoring training & 23 & $13 \%$ & & \\
\hline Trainer education & 5 & $3 \%$ & & \\
\hline Missing data & 1 & $1 \%$ & & \\
\hline
\end{tabular}

that correlations between items were sufficiently large for exploratory factor analysis [35]. An initial analysis was run to obtain eigenvalues for each component of the data. Six components had eigenvalues over Kaiser's criterion of 1 and in combination explained 59.92\% of the variance.

Solutions for six, five, and four factors were each examined using direct oblimin rotations of the factor loading matrix. The four-factor solution, which explained $52.37 \%$ of the variance, was chosen because the scree plot showed inflexions that justified retaining the four components and all items met the criterion of having a primary factor loading of 0.4 or above [35]. Table 4 shows the factor loadings after rotation.

Based on the explorative factor analysis, another structure in the dimensions of the KCSE scale emerged (Fig. 2). All items from the knowledge (items 15-21) and skills (items 22-28) subscales loaded on the first factor. The second factor includes items from the attitude (items 6-9) and dynamic state (item 11, 14) subscales. The third factor captures five items from the attitude (items 1-5) subscale. The fourth factor includes three items from the dynamic state (items 10,12,13) subscale.
Labeling of the factors is based on the theoretical underpinning of the study and reflects the theme of the factor items themselves: F1 knowledge \& skills (14 items), F2 (inter-) action (6 items), F3 attitude (5 items) and F4 self-regulation (3 items) (Fig. 2).

\section{Discussion}

The aim of this study was to develop and test the Kinaesthetics Competence Self-Evaluation (KCSE) scale. For the first time the relevant competence areas knowledge, skills, attitude, and dynamic state - for mobility care based on kinaesthetics are measurable in one instrument. In the KCSE scale all domains are equally important, which is reflected in the composition of the sum score (mean subscale scores add up to a sum score). Other self-evaluation instruments used in this field differ in their foci, e.g. the instrument developed by Kindblom-Rising et al. (2011) assesses nursing staff's movement and body awareness, attitude to the patient, to oneself and to work as well as reported behaviour. The questionnaire developed by Kneafsey et al. (2012) focuses on safety aspects of mobility care. Based on the content of the instruments it can be assumed that there 
Table 3 Descriptive and internal consistency results of the KCSE scale

\begin{tabular}{llllllll}
\hline Dimensions of KCSE scale & $\mathrm{n}$ & Score range & Mean (SD) & No of items & Cron-bach's alpha & Item-total correlation $r>0.20$ & $\begin{array}{l}\text { Inter-item correlations } \\
r>0.20 \& r<0.70\end{array}$ \\
\hline Attitude & 174 & $2.8-4$ & $3.6(0.27)$ & 9 & 0.63 & $8 / 9,89 \%$ & $12 / 36,33 \%$ \\
Dynamic state & 165 & $2.4-4$ & $3.4(0.40)$ & 5 & 0.54 & $4 / 5,80 \%$ & $6 / 10,60 \%$ \\
Knowledge & 172 & $1-4$ & $3.0(0.59)$ & 7 & 0.91 & $7 / 7,100 \%$ & $20 / 21,95 \%$ \\
Skills & 170 & $1.1-4$ & $3.0(0.50)$ & 7 & 0.86 & $7 / 7,100 \%$ & $21 / 21,100 \%$ \\
Total scale & 150 & $8.2-16.0$ & $13.0(1.44)$ & 28 & 0.91 & $24 / 28,86 \%$ & \\
\hline
\end{tabular}

Table 4 Corrected item-total correlations and factor analysis with direct oblimin rotation of the KCSE scale

\begin{tabular}{|c|c|c|c|c|c|c|}
\hline \multirow{2}{*}{$\begin{array}{l}\text { Item } \\
\text { No }\end{array}$} & \multirow[t]{2}{*}{ Abbreviated item $^{\text {a }}$} & \multirow{2}{*}{$\begin{array}{l}\text { Corrected } \\
\text { item-total } \\
\text { correlation }\end{array}$} & \multicolumn{4}{|c|}{ Rotated Factor Loadings } \\
\hline & & & F1 & $\mathrm{F} 2$ & F3 & $\mathrm{F} 4$ \\
\hline \multicolumn{7}{|c|}{ Attitude } \\
\hline 1 & Individual way of moving & .075 & -.010 & .013 & .594 & -.109 \\
\hline 2 & Ability to learn new movements & .363 & .349 & .012 & .614 & -.333 \\
\hline 3 & Movement support is a learning opportunity & .367 & .304 & .175 & .603 & -.141 \\
\hline 4 & Relationship of trust & .139 & .059 & .112 & .585 & .270 \\
\hline 5 & Independence & .248 & .161 & .233 & .549 & .013 \\
\hline 6 & Attentive interaction & .223 & .125 & .609 & -.209 & -.078 \\
\hline 7 & Interest in how the person in doing & .335 & .171 & .661 & .281 & -.032 \\
\hline 8 & Promote mobility & .430 & .289 & .694 & .240 & .096 \\
\hline 9 & Person can contribute own skills & .357 & .241 & .529 & .281 & .004 \\
\hline \multicolumn{7}{|c|}{ Dynamic state } \\
\hline 10 & Working with a kinaesthetics trainer or peer tutor & .487 & .454 & .423 & .065 & -.476 \\
\hline 11 & Trying it out myself & .487 & .428 & .608 & -.065 & -.317 \\
\hline 12 & Aware of my limits and request help & .147 & .019 & .417 & .078 & -.630 \\
\hline 13 & Feel helpless & .175 & .245 & .148 & -.050 & .609 \\
\hline 14 & Motivated to look for new ways & .414 & .307 & .531 & .182 & -.346 \\
\hline \multicolumn{7}{|c|}{ Knowledge } \\
\hline 15 & Knowledge about kinaesthetics sensory system & .767 & .829 & .337 & .203 & .133 \\
\hline 16 & Knowledge about elements of movement & .679 & .776 & .218 & .150 & .065 \\
\hline 17 & Knowledge about function of bones and muscles and stable body parts and joints & .637 & .764 & .088 & .179 & -.036 \\
\hline 18 & Knowledge about parallel and spiral types of movement & .587 & .752 & .013 & .035 & -.182 \\
\hline 19 & Knowledge about the concept of effort & .645 & .787 & .125 & -.018 & -.102 \\
\hline 20 & Knowledge about characteristics of movement in horizontal and vertical directions & .740 & .794 & .286 & .248 & -.088 \\
\hline 21 & Knowledge about the concept of environment & .653 & .775 & .086 & .188 & -.137 \\
\hline \multicolumn{7}{|l|}{ Skills } \\
\hline 22 & Focus on my own movement & .679 & .664 & .512 & .175 & -.006 \\
\hline 23 & Aware when I start lifting & .609 & .647 & .326 & .201 & .063 \\
\hline 24 & Aware when I take the lead & .646 & .747 & .254 & .128 & .209 \\
\hline 25 & Perceive and specifically change my movement patterns & .680 & .693 & .434 & .196 & .071 \\
\hline 26 & Support the person in using limbs for pulling and pushing & .612 & .626 & .369 & .238 & -.052 \\
\hline 27 & Support positioning & .659 & .673 & .454 & .148 & .191 \\
\hline 28 & Support "ongoing movement" & .596 & .670 & .366 & -.090 & .034 \\
\hline
\end{tabular}

${ }^{\mathrm{a}}$ English language translation of the original German items

F1 first factor, F2 second factor, F3 third factor, F4 fourth factor

Bold figures indicate the highest loading of an item on its theoretical component 


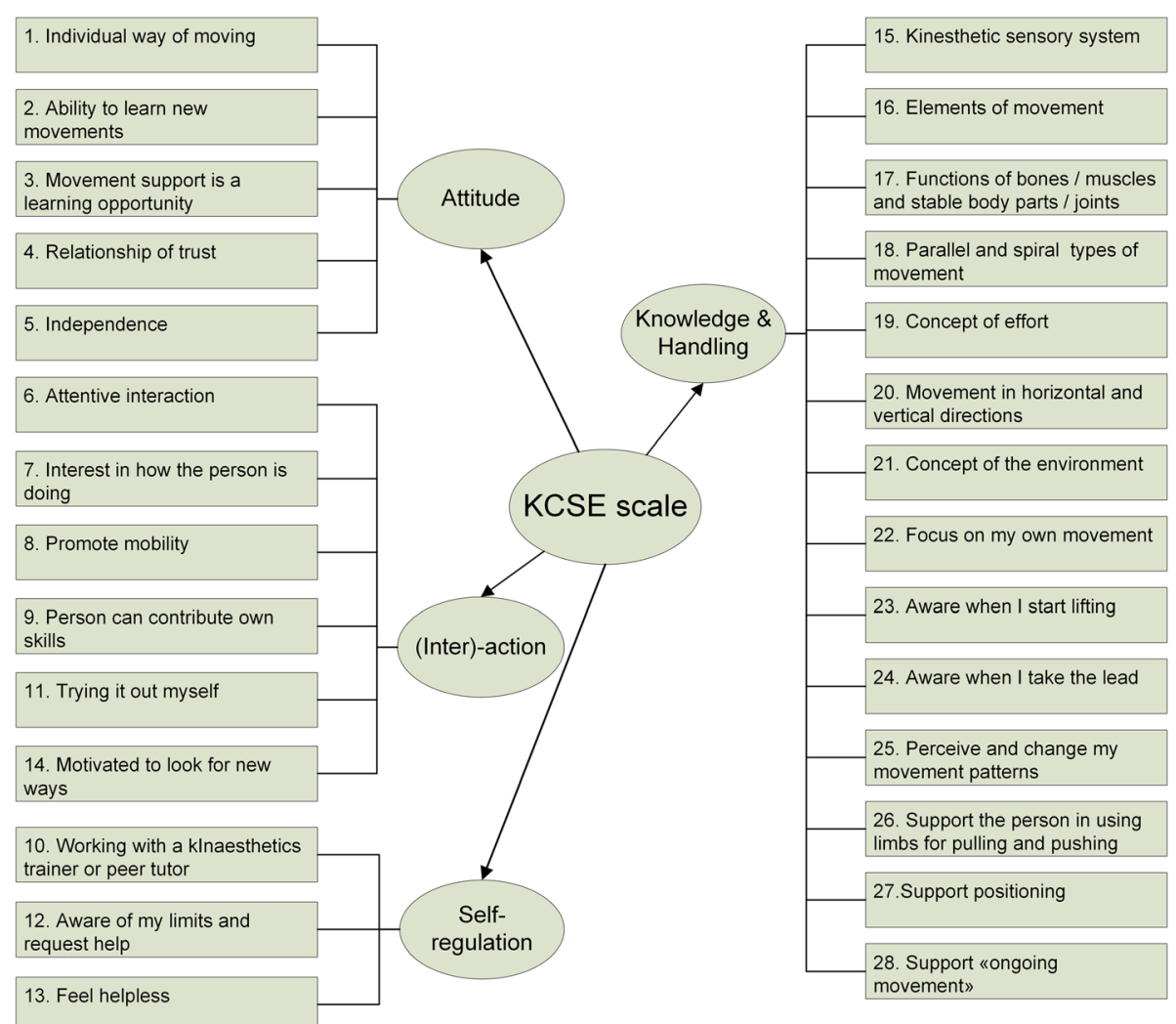

Fig. 2 Structure of the KCSE scale based on explorative factor analysis

are similarities between the different training approaches, e.g. the requirement to understand a care-dependent persons' mobility capacity [11] or the awareness of one's own movement [10]. However, it would be of great interest to condense elements from different training approaches to establish central elements reflecting high quality mobility care.

The new developed KCSE scale obtained appropriate values for internal consistency for the subscales attitude, knowledge and skills. The subscale dynamic state showed internal consistency values below the recommended 0.60 . The inter-item correlations varied, but most items of the subscales dynamic state, knowledge and skills showed acceptable values. However, $67 \%$ of the items from the subscale attitude did not reach the criterion for inter-item correlation of $r>0.20$ and $<0.70$. Values below 0.20 may not contribute significantly to the measurement of the concept, and those above 0.70 may be capturing only a small bandwidth of the construct [33]. Item-total correlations revealed four problematic items: item 1 (individual way of moving), item 4 (relationship of trust), item 12 (aware of my limits and seek help) and item 13 (feel helpless) showed item-total correlations below 0.2 . These items may not be sensitive enough to assess nursing staff's attitude and dynamic state related to mobility care. There is clearly a need to further assess the sensitivity of these items. The scale descriptives show that responses are not evenly distributed, but are skewed toward the upper end of the scale. Thus, a ceiling effect is possible and this means that it is difficult to detect any improvement, or distinguish among various grades of excellence [32]. In this study, more than $90 \%$ of the participants had passed a kinaesthetics training and the results indicate that the participants are confident with the ideas of the training. Further testing of the KCSE scale should be conducted in other samples (e.g. nursing staff working in hospital or home care), before considering another response category at the upper end of the scale.

In this study an exploratory factor analysis was conducted in order to explore the structure of the new measurement [34], showing that four factors explain $52 \%$ of the variance. These four factors show a logical connection to the theoretical framework of the instrument, although they differ slightly from the dimensions used during the design of the instrument. Items from the subscale knowledge and skills joined together to factor 1 . This is also theoretically plausible as these items reflect the knowledge and the application of the kinaesthetics concept system [36] and, therefore, are closely 
related to each other. The items of the subscales attitude and dynamic state are split into three different factors (factor 2, 3, and 4). There is a need for further analysis of the theoretical structure of the scale. The conceptual framework of competence in mobility care based on kinaesthetics is founded on literature and experts' judgement [15]. As this framework is a new development, it should be verified by further research.

\section{Limitations of the study}

An inherent limitation of any study in which participants are volunteers is the potential for non-response bias. Although the response rate was high in this study (84\%), non-respondent nursing staff might have responded differently to the KCSE scale. Furthermore, the sample included groups that were small (nursing students or nurses with kinaesthetics trainer education). Therefore, the reliability and validity results may not apply for these groups. The KCSE scale needs further testing in a larger and more diverse sample. Another limitation of our study is its cross-sectional design. Therefore, we are not yet able to establish the instrument's sensitivity to change in competence development.

\section{Practical implications}

The KCSE scale is a short (28 items) and easy to be administered instrument that can be used to assess nursing staff's attitude, dynamic state, knowledge and selfperceived skills in mobility care based on kinaesthetics. It can be applied for RNs, LPNs, nurse assistants and nursing aides with and without kinaesthetics training. The instrument has several potential applications for health care institutions aiming to foster high quality mobility care. First, the assessment of current mobility care practice from a self-evaluated perspective may highlight competencies that require training at an individual or institutional level. Second, the instrument may be used for reflective application, in order to facilitate nursing staff's awareness of possible discrepancies between their attitude, dynamic state, knowledge, and skills. Third, this assessment can help kinaesthetics trainers tailor the content and teaching strategies of training courses. Fourth, the self-evaluated competence can be compared with observed competence in kinaesthetics [37] to reinforce or dispel nursing staff's perceptions.

\section{Future research implications}

Several recommendations can be applied to the instrument to improve its validity and reliability and its relevance in other contexts. Based on further research in other samples, the theoretical structure of the instrument should be further analyzed and items and scale modification should be considered. The instrument should be tested within a confirmatory factor analysis and an adequate sample size [38]. In order to investigate the instrument's sensitivity to change, longitudinal studies should be conducted. Considering that supporting the mobility of care-dependent persons is the responsibility of the whole nursing team, it is of interest to investigate differences in larger and more diverse groups (e.g. nurse students or nursing aids) and to determine influencing factors (e.g. work experience). Subsequently, studies investigating the impact of higher levels of competence in kinaesthetics on patient outcomes (e.g. on functional mobility) should be conducted.

\section{Conclusion}

The newly developed KCSE scale is a promising instrument that can be used for measuring nursing staff's attitude, dynamic state, knowledge, and skills in mobility care based on kinaesthetics. The first psychometric testing showed good scale content validity $(\mathrm{S}-\mathrm{CVI}=0.93$ ) and acceptable reliability and validity results when administered by a sample of nursing staff in nursing home care.

Despite the need for further psychometric evaluation, the scale's application in clinical practice may be useful for identifying nursing staff's educational needs and evaluating personal growth in competence in mobility care based on kinaesthetics.

\section{Abbreviations}

CVI: Content validity index; I-CVI: Item content validity index:

KCSE: Kinaesthetics competence self-evaluation; S-CVI: Scale content validity index

\section{Acknowledgements}

We thank all the nursing care workers who participated. We especially thank the kinaesthetics experts for their continued commitment and support of the study.

\section{Funding}

This research received a grant from the public funding agency Gesundheitsförderung Schweiz (IP22.14).

\section{Availability of data and materials}

All data supporting the presented findings are included in this published article.

\section{Authors' contributions}

All authors have agreed on the final version and meet at least one of the following criteria as recommended by the International Committee of Medical Journal Editors: substantial contributions to conception and design $(H G, B S, H L K)$, acquisition of data $(H G)$, or analysis and interpretation of data (HG, BS, VH, SK, SO, HLK), drafting the article or revising it critically for important intellectual content (HG, BS, VH, SK, SO, HLK). All authors read and approved the final manuscript.

Ethics approval and consent to participate

Ethical approval was obtained from the ethics committee of the canton St. Gallen, Switzerland (EKSG 14/009 L) and permission to conduct the study was obtained from the heads of the nursing homes. The first author provided detailed information about the study during an information event at each of the study sites. In addition, written information was displayed in the wards. The return of the completed questionnaire was considered to be informed consent to participate in the study. 


\section{Consent for publication}

Not applicable.

\section{Competing interests}

The authors declare that they have no competing interests.

\section{Publisher's Note}

Springer Nature remains neutral with regard to jurisdictional claims in published maps and institutional affiliations.

\section{Author details}

${ }^{1}$ Finnish Doctoral Programme in Nursing Science, Department of Nursing Science, University of Turku, Turku, Finland. Institute of Applied Nursing Sciences, University of Applied Sciences FHS St. Gallen, Rosenbergstrasse 59 Postfach, 9001 St. Gallen, Switzerland. ${ }^{3}$ Institute of Applied Nursing Sciences, University of Applied Sciences FHS St.Gallen, St. Gallen, Switzerland. ${ }^{4}$ Research Affiliate Sydney Nursing School, University of Sydney, Sydney, Australia. ${ }^{5}$ Adjunct Professor Department of Nursing Science, University of Turku, Turku, Finland. ${ }^{6}$ Research Affiliate Institute of Applied Nursing Sciences, University of Applied Sciences FHS St. Gallen, St. Gallen, Switzerland. Institute for Social Medicine and Epidemiology, Nursing Research Unit, University of Lübeck, Lübeck, Germany. ${ }^{8}$ University of Applied Sciences FHS St. Gallen, St. Gallen, Switzerland. ${ }^{9}$ Department of Nursing Science, University of Turku, Turku, Finland. ${ }^{10}$ Turku University Hospital, Turku, Finland.

Received: 23 February 2017 Accepted: 3 November 2017

Published online: 21 November 2017

\section{References}

1. Palese A, Menegazzi G, Tullio A, Zigotti M, Hayter M, Watson R. Functional decline in residents living in nursing homes: a systematic review of the literature. J Am Med Dir Assoc. 2016;17:694-705

2. Taylor J, Sims J, Haines TP. The influence of protection, palliation and costs on mobility optimization of residents in nursing homes: a thematic analysis of discourse. Int J Nurs Stud. 2012:49:1364-74.

3. Rantakokko M, Mänty M, Rantanen T. Mobility decline in old age. Exerc Sport Sci Rev. 2013;41:19-25.

4. Brown CJ, Flood KL. Mobility limitation in the older patient: a clinical review. JAMA. 2013:310:1168-77.

5. James BD, Boyle PA, Buchman AS, Bennett DA. Relation of late-life social activity with incident disability among community-dwelling older adults. J Gerontol A Biol Sci Med Sci. 2011:66:467-73.

6. Lahmann NA, Tannen A, Kuntz S, Raeder K, Schmitz G, Dassen T, Kottner J. Mobility is the key! Trends and associations of common care problems in German long-term care facilities from 2008 to 2012. Int J Nurs Stud. 2015;52: 167-74.

7. Bourret EM, Bernick LG, Cott CA, Kontos PC. The meaning of mobility for residents and staff in long-term care facilities. J Adv Nurs. 2002;37:338-45.

8. Taylor J, Sims J, Haines TP. The emergent relevance of care staff decisionmaking and situation awareness to mobility care in nursing homes: an ethnographic study. J Adv Nurs. 2014;70:2767-78.

9. Taylor J, Sims J, Haines TP. I accept it staff assistance; no choice': an ethnographic study of residents' attitudes towards mobility within nursing homes. Int J Older People Nursing. 2014;9:258-68.

10. Kindblom-Rising K, Wahlström R, Nilsson-Wikmar L, Buer N. Nursing staff's movement awareness, attitudes and reported behaviour in patient transfe before and after an educational intervention. Appl Ergon. 2011:42:455-63.

11. Taylor J, Barker A, Hill H, Haines TP. Improving person-centered mobility care in nursing homes: a feasibility study. Geriatric nursing (New York, NY). 2015;36:98-105

12. Hatch F, Maietta L. Kinästhetik: Gesundheitsentwicklung und menschliche Aktivitäten. 2nd ed. Urban und Fischer: München, Jena; 2003.

13. Enke A, Knobel S, Marty-Teuber S. Kinaesthetics: Lernen und Bewegungskompetenz. 1st ed. European Kinaesthetics Association EKA: Linz; 2010.

14. Fringer $A$, Huth $M$, Hantikainen V. Nurses' experiences with the implementation of the Kinaesthetics movement competence training into elderly nursing care: a qualitative focus group study. Scand J Caring Sci. 2014:28:757-66.
15. Gattinger H, Leino-Kilpi H, Köpke S, Teuber-Marty S, Senn B, Hantikainen V Nurses' competence in kinaesthetics: a concept development. Z Gerontol Geriatr. 2016;

16. Johnsson C: The patient transfer task. Methods of assessing work technique. Thesis. Karolinska Institute, department of Nursing; 2005.

17. Fringer A, Huth M, Hantikainen V. Nurses' learning experiences with the Kinaesthetics care concept training in a nursing home. A qualitative descriptive study. Educ Gerontol. 2015;41:888-902.

18. Taylor J, Hill H, Kay K. An integrated practice approach to mobility care for older people. Nursing standard (Royal College of Nursing (Great Britain): 1987). 2016, 30:51-9; quiz 60

19. McCrorie P, Roberts PA, Sainsbury D, Boldy D, Gower S. Perceptions of nursing and physical therapy students toward peer-led Interprofessional education in manual handling. Nurse Educ. 2017;42:E1-6.

20. Kindblom-Rising K, Wahlstrom R, Ekman S. Nursing staff's perception of changes in patient transfer habits after a course - a phenomenologicalhermeneutic study. Ergonomics. 2007;50:1017-25.

21. Kneafsey RA. Systematic review of nursing contributions to mobility rehabilitation: examining the quality and content of the evidence. J Clin Nurs. 2007;16:325-40.

22. Ekblad M, Wijk H, Ivanoff SD. Experiences of physical strain during person transfer situations in dementia care units. Scand J Caring Sci. 2009:23:64450

23. Long AF, Kneafsey R, Ryan J, Berry J. Exploring qualified nurses' perceptions of the relevance of education in preparation for their role in rehabilitation. Nurse Educ Today. 2002;22:136-43.

24. Kneafsey R, Haigh C. Moving and handling rehabilitation patients. A survey of nurses' views. Int J Therapy Rehab. 2009;16:431-41.

25. Betschon E, Brach M, Hantikainen V. Studying feasibility and effects of a two-stage nursing staff training in residential geriatric care using a 30 month mixed-methods design [ISRCTN24344776]. BMC Nurs. 2011;10:10.

26. Kneafsey R, Ramsay J, Edwards H, Callaghan H. An exploration of undergraduate nursing and physiotherapy students' views regarding education for patient handling. J Clin Nurs. 2012;21:3493-503.

27. Polit DF, Beck CT. The content validity index: are you sure you know what's being reported? Critique and recommendations. Res Nurs Health. 2006;29: 489-97.

28. Gattinger $\mathrm{H}$. Development and evaluation of two instruments to assess nursing staff's competence in mobility care based on kinaesthetics. University of Turku: Annales Universitatis Turkuensis; 2017.

29. American Educational Research Association. Standards for educational and psychological testing. Washington, DC: American Educational Research Association; 2014.

30. Zúñiga F, Ausserhofer D, Hamers JPH, Engberg S, Simon M, Schwendimann R. Are staffing, work environment, work stressors, and rationing of care related to care Workers' perception of quality of care? A cross-sectional study. J Am Med Dir Assoc. 2015;16:860-6.

31. Grove SK, Burns N, Gray J. The practice of nursing research: appraisal, synthesis, and generation of evidence. 7th ed. Elsevier/Saunders: St. Louis, Missouri; 2013.

32. Streiner DL, Norman GR. Health measurement scales: a practical guide to their development and use. 3rd ed. Oxford, New York: Oxford University Press; 2003.

33. Bowling A. Research methods in health: investigating health and health services. Milton Keynes: Open University Press; 2014

34. Watson R. Publishing the results of factor analysis: interpretation and presentation. J Adv Nurs. 1998:28:1361-3.

35. Field A. Discovering statistics using IBM SPSS statistics. 4th ed. London: Sage; 2013.

36. Suter R, Marty-Teuber B, Knobel S, Marty-Teuber S. Kinaesthetics Konzeptbuch. European Kinaesthetics Association: Linz; 2010.

37. Gattinger H, Leino-Kilpi H, Hantikainen V, Kopke S, Ott S, Senn B. Assessing nursing staff's competences in mobility support in nursing-home care: development and psychometric testing of the Kinaesthetics competence (KC) observation instrument. BMC Nurs. 2016:15:65.

38. MacCallum RC, Widaman KF, Zhang S, Hong S. Sample size in factor analysis. Psychol Methods. 1999:84-99. 